\title{
Characteristics in patients with headache in an outpatient clinic in Japan
}

\author{
Toshikatsu Okumura*, Sachie Tanno, Masumi Ohhira, Satoshi Tanno, Tsukasa Nozu
}

\begin{abstract}
Background: Little is known about the prevalence of primary and secondary headache in clinics in Japan. The aim of this study is to characterize patients with headache in an outpatient unit where primary care physicians are working in Japan.

Methods: Consecutive outpatients who newly visited the Department of General Medicine, Asahikawa Medical College Hospital, Asahikawa, Japan between April 2005 and March 2009 were analyzed. Each parameter such as age, sex or diagnosis was investigated.
\end{abstract}

Results: Out of 4693 patients, 418 patients visited to our department because of headache. Primary headache was found in 167 patients (39.9\%). The rate of tension-type headache (TTH) (30.8\%) was highest, followed by migraine (9.1\%). Approximately 3 times higher rate of migraine was observed in female patients when compared with male patients. In female patients, migraine was observed more frequently in younger patients. On the other hands, $\mathrm{TH}$ was observed in almost all aged patients in males and females, and the rate of TTH peaks between the ages of 40 and 49 years in both sex. The present study also demonstrated that $8.4 \%$ of patients who chiefly complained of headache had been diagnosed as depression while $1.7 \%$ of remained patients had been diagnosed as depression, indicating 5-times higher rate of depression in patients with headache.

Conclusion: All these results suggest that primary headache, especially $T \mathrm{TH}$, is highly observed and depression should be considered in patients with headache in an outpatient clinic where primary care physicians are working in Japan.

\section{Background}

Headache is the most prevalent neurological symptom and is experienced by almost everyone [1]. Populationbased epidemiological studies on primary headache have been carried out in many countries [2]. Stovner et al. have described in the review article that there exists a regional differences in the prevalence of primary headache [2]. For example, the prevalence of tension type headache (TTH) in the adults in Europe is much higher than other regions including North America and Asia, and the prevalence of migraine in Asia is lower than Europe and North America. Although there are two reports on the prevalence of primary headache such as migraine in general population in Japan $[3,4]$, little is known about the prevalence of not only primary headache such as migraine and TTH but also secondary

\footnotetext{
* Correspondence: okumurat@asahikawa-med.ac.jp
Department of General Medicine, Asahikawa Medical University, Asahikawa,

* Correspondence: okumurat@asahikawa-med.ac.jp
Department of General Medicine, Asahikawa Medical University, Asahikawa, Japan
}

(c) 2010 Okumura et al; licensee BioMed Central Ltd. This is an Open Access article distributed under the terms of the Creative Commons Attribution License (http://creativecommons.org/licenses/by/2.0), which permits unrestricted use, distribution, and reproduction in any medium, provided the original work is properly cited.

\section{Methods}

We analyzed consecutive outpatients who newly visited at Department of General Medicine, Asahikawa Medical College Hospital. In Japan, almost everyone is covered by national health insurance. Patients generally have the freedom to choose the health care provider that feel best fits their needs without concerns regarding costs. Therefore, there might be no big difference between patients who visit the department of General Medicine in Asahikawa Medical College hospital and ones who visit clinics or smaller hospitals. The total number of patients during April 2005 and March 2009 evaluated in this study was 4693. As reported previously [5,6], Asahikawa Medical College Hospital is located in Asahikawa 
City which has a population of approximately 350,000 in the middle of the Hokkaido Island, the most northern part of Japan. The hospital consists of 602 beds in which approximately 250 doctors are working to cover almost all of medical problems. Among them, 5 or 6 primary care physicians are working at the Department of General Medicine. New patients who come to the hospital by an ambulance are always admitted to the emergency unit in this hospital. Therefore, such patients are not admitted in the department of General Medicine. Out of new walk-in patients who visited to outpatient departments in our hospital, the patients who have a letter from other doctors to a specific department such as the department of Dermatology go to directly to the department. On the other hand, patients who have no letter from other doctors and do not know "I should visit to what department" come first to the Department of General Medicine. In our recent paper [5], evaluated outpatients who visited the Department of General Medicine were classified into the major ICD-10. Thus a large variety of patients visited to the Department of Medicine, Asahikawa Medical College Hospital, Japan.

All data were drawn from medical records and Computerized Physician Order Entry System in the hospital. Each parameter such as age, sex and diagnosis was investigated from the source. All patients who accepted for examination of laboratory test, we measured routinely urine and blood samples. These include complete blood count, liver function, renal function, $\mathrm{C}$-reactive protein and TSH. To exclude the secondary headache, patients who complained of symptoms such as headache with increasing intensity, sudden onset and/or headache that had been never experienced before, were received brain CT scan to rule out brain diseases. Rapid test for influenza virus, blood test for detection of EB virus or culture tests that had been considered to be necessarily for differential diagnosis was performed in patients who had obvious signs of acute infection, like fever of $\geq 37.0^{\circ}$ $\mathrm{C}$ within a couple of days. The International Classification of Headache Disorders version 2 (ICDH-II) [7] was applied to each patient who complained of headache.

Depression and other psychiatric disorders were diagnosed according to DSM-IV [8]. Due to the clinical limitation, DSM-IV classification did not apply for all patients. For instance, patients with acute fever, abdominal pain and watery diarrhea were diagnosed as acute enterocolitis without DSM-IV classification. As one may speculate, we could not exclude the possibility if the patient might be depression then. Thus, there was a clinical limitation when the patients visited to our clinic. In fact, DSM-IV classification was applied to patients who complained headache chronically. On the other hands, it is certain that a part of patients who complained symptoms other than headache were diagnosed as depression. When we wonder if the patient may be depression because we observed appetite loss, sleep disturbance, unexplained body weight loss, recent suicide attempt, our feeling "He/She looks depressive" and so on, final diagnosis of depression have been done according to DSM-IV. Statistical analysis was made using $\chi$ square test using IBM SPSS statistics software for Windows version 18.0 (SPSS Inc., Chicago, USA). A level of $\mathrm{p}<0.05$ was considered to be statistically significant.

\section{Results}

Out of 4693 patients, 418 (8.9\%) patients visited because of headache. CT scan or MRI imaging to detect or exclude brain disorders was performed in 85 patients (20. 3\%) out of the 418 patients. Final diagnosis of 418 patients was shown in Table 1 . The present results demonstrated that cerebrovascular disorders had been rarely observed in patients who complained of headache as shown in Table 1. Primary headache was found in 167 patients (39.9\%). The rate of TTH was highest, followed by migraine. Secondary headache was found as in Table 1. These include systemic infection such as influenza and common colds, rhino sinusitis or depression. Psychiatric disorders other than depression include schizophrenia and, neurotic and somatoform disorders. When systemic infection is excluded, the rate of primary headache such as TTH and migraine out of all patients with headache is $49.4 \%$ (167/338), and the prevalence of primary headaches and depression is approximately $60.0 \%(202 / 338)$.

Table 1 Diagnosis of patients who had headache

\begin{tabular}{|c|c|c|c|}
\hline \multicolumn{2}{|l|}{ ICHD-II diagnosis } & \multirow{2}{*}{$\begin{array}{r}\text { Number } \\
38\end{array}$} & \multirow{2}{*}{$\begin{array}{r}\text { (\%) } \\
9.1\end{array}$} \\
\hline Migraine & & & \\
\hline Tension-type headache & & 129 & 30.8 \\
\hline cerebrovascular disorder & & 3 & 0.7 \\
\hline non-vascular intracranial disorder & & 2 & 0.5 \\
\hline systemic infection (bacterial or viral) & & 80 & 19.1 \\
\hline \multirow[t]{2}{*}{ disorder of homoeostasis } & thyroid & 3 & 0.7 \\
\hline & hypertension & 5 & 1.2 \\
\hline \multirow[t]{2}{*}{ eyes, ears, nose, sinuses, structures } & $\begin{array}{l}\text { acute } \\
\text { glaucoma }\end{array}$ & 1 & 0.2 \\
\hline & rhinosinusitis & 11 & 2.6 \\
\hline \multirow[t]{2}{*}{ psychiatric disorder } & depression & 35 & 8.4 \\
\hline & others & 29 & 6.9 \\
\hline $\begin{array}{l}\text { Cranial neuralgias and central causes of } \\
\text { facial pain }\end{array}$ & $\begin{array}{l}\text { herpes } \\
\text { zoster }\end{array}$ & 7 & 1.7 \\
\hline Others & & 75 & 17.9 \\
\hline Total & & 418 & \\
\hline
\end{tabular}


Table 2 Gender and age distribution of migraine, tension type headache and depression

\begin{tabular}{|c|c|c|c|c|c|c|}
\hline & \multirow[t]{2}{*}{ Age } & \multirow[t]{2}{*}{ Total patient } & & & \multicolumn{2}{|c|}{ Tension type } \\
\hline & & & Migraine & & Headache & Depression \\
\hline \multicolumn{7}{|l|}{ Male } \\
\hline & $10-19$ & 112 & & 0 & 0 & ( \\
\hline & $20-29$ & 331 & $4(1.2 \%)$ & & $6(1.8 \%)$ & $3(0.9 \%)$ \\
\hline & $30-39$ & 330 & $3(0.9 \%)$ & & $10(3.0 \%)$ & $3(0.9 \%)$ \\
\hline & $40-49$ & 203 & & 0 & $8(3.9 \%)$ & $5(2.5 \%)$ \\
\hline & $50-59$ & 268 & & 0 & $6(2.2 \%)$ & $2(0.7 \%)$ \\
\hline & $60-69$ & 313 & & 0 & $3(1.0 \%)$ & ( \\
\hline & 70-79 & 249 & & 0 & $5(2.0 \%)$ & $2(0.8 \%)$ \\
\hline & 80- & 93 & & 0 & $1(1.0 \%)$ & ( \\
\hline & all & 1930 & $7(0.4 \%)$ & & 39 (2.0\%) & $15(0.8 \%)$ \\
\hline
\end{tabular}

Female

$\begin{array}{lllll}10-19 & 165 & 3(1.8 \%) & 7(4.2 \%) & 1(0.6 \%) \\ 20-29 & 476 & 9(1.9 \%) & 19(4.0 \%) & 3(0.6 \%) \\ 30-39 & 480 & 9(1.9 \%) & 15(3.1 \%) & 4(0.8 \%) \\ 40-49 & 289 & 4(1.4 \%) & 14(4.8 \%) & 2(0.7 \%) \\ 50-59 & 413 & 5(1.2 \%) & 10(2.4 \%) & 3(0.7 \%) \\ 60-69 & 401 & 1(0.2 \%) & 13(3.2 \%) & 1(0.2 \%) \\ 70-79 & 375 & 0 & 7(1.9 \%) & 4(1.1 \%) \\ 80- & 143 & 0 & 3(2.1 \%) & 2(1.4 \%) \\ & 2763 & 31(1.1 \%) & 88(3.2 \%) & 20(0.7 \%) \\ \text { all } & 4693 & 38(0.8 \%) & 134(2.9 \%) & 35(0.7 \%) \\ & \text { Total } & & & \end{array}$

Table 2 summarized the data on the gender and age distribution of migraine, TTH and depression who complained of headache in the present study. Based on the Table 2, the rate of migraine and $\mathrm{TTH}$ in all patients was 0.8 or $2.9 \%$, respectively, indicating $\mathrm{TTH}$ is the highest prevalence in this study. With regard to the relationship between sex or age, and the number of patients with migraine and TTH, there was a significant gender difference in the frequency of migraine in all aged patients (male vs. female, $0.4 \%$ vs $1.1 \%$ ), indicating a higher rate of migraine in female patients. It was also shown that migraine was limited to patients aged 20-39 years old in male patients. In female patients, migraine was observed more frequently in patients aged 20-39 years old. There were significant numbers of migraine older than 40 years in women but not in men. On the other hands, the rate of TTH was 1.6 times higher in female than male. Although TTH was observed in almost all aged patients in males and females, the rate of TTH peaks between the ages of 40 and 49 years in men and women.
Table 3 Incidence of depression in patients who complained of headache or others

\begin{tabular}{lcc}
\hline \multicolumn{2}{c}{$(\mathbf{A})$ Chief symptom } & (B) Depression (B/A \%) \\
\hline Hadache & 418 & $35(8.4 \%)$ \\
Others & 4275 & $71(1.7 \%)$ \\
Total & 4693 & $106(2.3 \%)$ \\
\hline
\end{tabular}

*, $\mathrm{p}<0.001$, when compared with others.

Table 3 shows the incidence of depression in patients who complained of headache. As demonstrated, $8.4 \%$ of patients who chiefly complained of headache had been diagnosed as depression while $1.7 \%$ of remained patients had been diagnosed as depression. The rate of depression was significantly high in patients with headache.

\section{Discussion}

Out of 4693 patients, headache was the chief complaint in 418 patients $(8.9 \%)$, indicating that diagnosis and treatment for headache is one of the most important clinical issues in outpatient units in Japan.

According to this study, approximately $50 \%$ or $60 \%$ if systemic infection was excluded out of patients with headache were diagnosed as primary headache such as TTH and migraine, and depression. We should therefore consider the three disorders, TTH, migraine, and depression, as major causes of headache in this particular clinical setting in Japan.

With regard to the prevalence of primary headache such as migraine and $\mathrm{TTH}$, a number of reports have been published in many countries. Murtaza et al. [9] have demonstrated that out of 255 consecutive patients who presented to a headache clinic at a tertiary care hospital in Pakistan, migraine was the most common disorder (206 patients) followed by TTH (58 patients). According to a report by a Brazilian tertiary-care center [10], the prevalence of diagnosis in patients with headache were migraine (38\%) and TTH (22\%), respectively. Thus, in Pakistan and Brazil, migraine is the highest prevalence in patients with headache. However, in a large majority of countries, TTH is the highest prevalence in patients with headache [2].

A population-based survey in Japan (the Disen study) revealed the 1-year prevalence of migraine and $\mathrm{TTH}$ was $6.0 \%$ and $21.7 \%$, respectively (4). A nationwide survey in Japan by Sakai et al. [3] have demonstrated that overall prevalence of migraine and $\mathrm{TTH}$ was $8.4 \%$ and $22.4 \%$, respectively. The present findings obtained from an outpatient clinic-based study revealed migraine and TTH was diagnosed in $9.1 \%$ and $30.8 \%$ out of patients who complained of headache, respectively. These results suggest approximately 3 times higher prevalence of 
TTH than migraine not only in general population but also in outpatient units in Japan.

Jensen et al. [2] have demonstrated that the male: female ratio for migraine among adults varies from 1:2 to 1:3. A nationwide survey of migraine in the general population in Japan [3], the male: female ratio was 1: 3.6. The present study showed that male: female ratio for migraine was 1: 2.75 , supporting the higher risk of migraine in female than male.

It has been demonstrated in the recent review that the male: female ratio for TTH is 4:5, indicating that unlike for migraine, women are only slightly more affected than men [2]. In the present study, male: female ratio for TTH was 1: 1.6, furthermore supporting that women are only slightly more affected by TTH than men, when compared with migraine.

With regard to the relation of age and the prevalence of migraine, it has been shown that the highest prevalence of migraine was in women in their 30's, in whom one in five suffered migraine [1]. The present study similarly showed that migraine was observed higher in women in 20's and 30's. On the other hand, the rate of TTH peaks between the ages of 40 and 49 years in men and women. These results suggest that there are gender and age-dependent differences in the prevalence of between migraine and TTH.

Takeshima et al. [4] have demonstrated that 1-year prevalence of migraine was $6.0 \%$, but less than $10 \%$ of migraine had consulted a physician in Japan. According to the report by Sakai et al. [3], nationwide survey of migraine was performed in Japan and demonstrated that the overall prevalence of migraine in the past year was $8.4 \%$ while doctor attendance rate was very low and approximately $70 \%$ with migraine had never consulted a physician for headache. The present study showed that migraine was diagnosed in only $0.8 \%$ out of all patients. Although there is a much difference in the prevalence of migraine in between the general population $(6.0 \%$ and $8.4 \%)$ reported previously and outpatients $(0.8 \%)$ examined in this study, the difference might be explained by the evidence that only a small part of migraine consult or seek medical service as described in above at least in Japan.

The present results also demonstrated that cerebrovascular disorders had been rarely observed in patients who complained of headache. The reason may come from the features in this hospital that a large majority of patients with severe headaches who might have cranial vascular diseases visited to our hospital by ambulance. Doctors in emergency room take care of the patients who come by ambulance. In this study, we analyzed the data of walk-in patients in this outpatient department. These are the reasons why cranial vascular diseases were rare in this study.
One may speculate whether diagnosis of depression was performed adequately in this study. We have recently published a paper on patients with prescription of selective serotonin reuptake inhibitor (SSRI)s, antidepression drugs, in our clinic [5]. As described in the paper, SSRIs were prescribed to $126(2.7 \%)$ patients out of all 4670 patients during 4 years. The percentage might be acceptable because major depression is seen by primary care physicians with a prevalence of approximately $5 \%$ in adult patients in western countries [11-13]. We would therefore suggest the ability of accurate diagnosis of depression would not be far from the estimated percentage of depression in our clinic.

The present study revealed that $8.4 \%$ out of patients who chiefly complained of headache were diagnosed as depression. On the other hand, $1.7 \%$ out of remained patients who chiefly complained of symptoms other than headache were depression, suggesting approximately 5 times higher prevalence of depression in patients with headache. Marlow et al. [14] have reported that $32 \%$ of patients with headache were depression whereas $12 \%$ patients without headache were depression, indicating 3-times higher prevalence of depression in patients with headache, supporting our present results. Chung et al. [15] have demonstrated that patients who presented with a chief complaint of headache in the outpatient family practice setting were found to have a high prevalence of depression. These evidence suggest that headache would be a marker of depression in the primary care setting also in Japan.

\section{Conclusion}

As shown in this study, a majority of patients who visited to our outpatient unit because of headache were diagnosed as TTH and migraine, and depression. The epidemiological characteristics may help our daily clinical practice in outpatient units where primary care physicians are working in Japan.

\section{Acknowledgements}

We would like to thank Dr. Y. Saijo (Department of Health Science, Asahikawa Medical University, Japan) for asistance of statistical analysis.

\section{Authors' contributions}

TO conceptualized, designed, collected and analyzed data and drafted the manuscript. ST, MO, ST and TN contributed to collection and analysis of data. All authors read and approved the final manuscript.

\section{Competing interests}

The authors declare that they have no competing interests.

Received: 5 August 2010 Accepted: 18 November 2010 Published: 18 November 2010

\section{References}

1. Jensen R, Stovner L: Epidemiology and comorbidity of headache. Lancet Neurol 2008, 7:354-361. 
2. Stovner L, Hagen K, Jensen R, Katsarava Z, Lipton R, Scher A, Steiner T, Zwart JA: The global burden of headache: a documentation of headache prevalence and disability worldwide. Cephalalgia 2007, 27:193-210.

3. Sakai F, Igarashi H: Prevalence of migraine in Japan: a nationwide survey. Cephalalgia 1997, 17:15-22.

4. Takeshima T, Ishizaki K, Fukuhara Y, Ijiri T, Kusumi M, Wakutani Y, Mori M, Kawashima M, Kowa H, Adachi Y, Urakami K, Nakashima K: Populationbased door-to-door survey of migraine in Japan: the Daisen study. Headache 2004, 44:8-19.

5. Tanno S, Ohhira M, Tsuchiya Y, Takeuchi T, Tanno S, Okumura T: Frequent early discontinuation of SSRI prescribed by primary care physicians in young males in Japan. Intern Med 2009, 48:1263-1266.

6. Okumura T, Tanno S, Ohhira M, Tanno S: Prevalence of functional dyspepsia in an outpatient clinic with primary care physicians in Japan. J Gastroenterol 2010, 45:187-194.

7. Headache Classification Subcommittee of the International Headache Society: The International Classification of Headache Disorders. Cephalagia; 2 2004:24(Suppl 1):9-160.

8. International Classification of Diseases $10^{\text {th }}$ edition (ICD-10) codes. International Statistical Classification of Diseases and Related Health Problems, 10th Revision, Version for; 2007 [http:/www.who.int/ classifications/apps/icd/icd10online/].

9. Murtaza M, Kisat M, Daniel H, Sonawalla AB: Classification and clinical features of headache disorders in Pakistan: a retrospective review of clinical data. PLoS One 2009, 4:e5827.

10. Felício AC, Bichuetti DB, Santos WA, Godeiro Junior Cde O, Marin LF, Carvalho Dde S: Epidemiology of primary and secondary headaches in a Brazilian tertiary-care center. Arq Neuropsiquiatr 2006, 64:41-44.

11. Williams JW Jr, Mulrow CD, Kroenke K, Dhanda R, Badgett RG, Omori D, Lee $\mathrm{S}$ : Case-finding for depression in primary care: randomized trial. Am J Med 1999, 106:36-43.

12. Simon GE, Vonkoff M: Recognition, management, and outcomes of depression in primary care. Arch Fam Med 1995, 4:99-105.

13. Whooley MA, Avins AL, Miranda J, Browner WS: Case-finding instruments for depression, two questions are as good as many. J Gen Intern Med 1997, 12:439-445.

14. Marlow RA, Kegowicz CL, Starkey KN: Prevalence of depression symptoms in outpatients with a complaint of headache. J Am Board Fam Med 2009, 22:633-637.

15. Chung MK, Kraybill DE: Headache: a marker of depression. J Fam Pract 1990, 31:360-364

doi:10.1186/1447-056X-9-10

Cite this article as: Okumura et al: Characteristics in patients with headache in an outpatient clinic in Japan. Asia Pacific Family Medicine 2010 9:10.

\section{Submit your next manuscript to BioMed Central and take full advantage of:}

- Convenient online submission

- Thorough peer review

- No space constraints or color figure charges

- Immediate publication on acceptance

- Inclusion in PubMed, CAS, Scopus and Google Scholar

- Research which is freely available for redistribution 